\title{
Alloy design of ductile phosphoric iron: Ideas from archaeometallurgy
}

\author{
GOUTHAMA and R BALASUBRAMANIAM* \\ Advanced Centre for Materials Science, *Department of Materials and Metallurgical Engineering, Indian Institute of \\ Technology, Kanpur 208 016, India
}

MS received 3 May 2003

\begin{abstract}
Alloy design criteria to produce ductile phosphoric irons have been proposed based on a detailed microstructural study of ancient Indian irons. The alloy design aims at avoiding phosphorus segregation to the grain boundaries by (a) soaking the phosphoric iron at high temperatures within the ferrite + austenite region to precipitate austenite allotriomorphs, (b) utilizing a critical amount of carbon to segregate to grain boundaries, and (c) precipitation of some of the phosphorus in solid solution in the ferrite matrix as fine coherent phosphide precipitates.
\end{abstract}

Keywords. Ancient Indian iron; transmission electron microscopy; phosphoric iron; microstructure; alloy design.

\section{Introduction}

It has generally been considered that phosphorus in steels is deleterious to the mechanical properties of the material at ambient temperatures and strictly avoided in modern iron and steel making. Several eminent metallurgists considered phosphorus 'treacherous' (Stead 1918). It produces cold shortness or brittleness during cold working (but does not produce hot shortness, and therefore can be processed at high temperatures). It is for this reason that its content in modern steels is controlled to < $0.04 \mathrm{wt} . \%$ (Boyer and Gall 1990). Although the exact mechanism is still not clear, it has been established that the embrittlement of P-containing steels is due to $\mathrm{P}$ segregation to the grain boundaries (Inman and Tipler 1958; Sakurai et al 1981; Haensel and Grabke 1986; Menyhard 1992). P reduces grain boundary cohesion and promotes intergranular failure. Moreover, the degree of embrittlement is dependent on heat treatment history of the material. Steels are susceptible to intergranular failure when annealed in or allowed to cool slowly through the temperature range $600-400^{\circ} \mathrm{C}$ (which has been called as temper embrittlement) (Josefsson 1954; Allen 1963; Suzuki et al 1985; Dieter 1988; Honeycombe and Bhadeshia 1995). The worst embrittlement occurs when both $\mathrm{P}$ and $\mathrm{C}$ are present in significant amounts. The present communication will address phosphoric irons, implying iron with significant phosphorus contents and practically low carbon contents. Interestingly, in the case of phosphoric irons, the ductility depended on cycling through the austenite-ferrite transformation and a slow cooling rate appears to increase ductility (Stewart et al 2000).

*Author for correspondence
Therefore, the alloy design (with its attendant heat treatment) philosophies for Fe-P alloys to reduce embrittlement are anticipated to be quite different from those for $\mathrm{Fe}-\mathrm{C}$ alloys. It is emphasized at the outset that the phase equilibria in the $\mathrm{Fe}-\mathrm{P}$ phase diagram, rather than the $\mathrm{Fe}-\mathrm{C}$ diagram, would be considered.

An interesting variety of $\mathrm{Fe}-\mathrm{P}$ alloys are archaeological irons, because they contain higher $\mathrm{P}$ contents than modern steels. Ancient archaeological phosphoric irons, from several different parts of the world, contain between 0.05 to $0.5 \mathrm{wt} . \% \mathrm{P}$ and levels of up to $1 \mathrm{wt} . \%$ have also been detected (Tylecote 1986; Mcdonnel 1989; Balasubramaniam 2002). It has been suggested that the ancients deliberately chose phosphoric iron for manufacturing a wide variety of objects (Stewart et al 2000). Although the ancient phosphoric irons might have been susceptible to embrittlement on impact, they, nevertheless, provided serviceable tools. Interestingly, most of the archaeological phosphoric irons possess very low carbon contents (Tylecote 1986; Mcdonnel 1989; Balasubramaniam 2002). The origin of high phosphorus contents (and also the corresponding low carbon contents) in ancient archaeological irons has been elucidated recently based on rigorous thermodynamic analysis (Kumar and Balasubramaniam 2002). It has been established that higher phosphorus contents obtained were because limestone was not used in the charge of the ancient bloomery furnaces (Kumar and Balasubramaniam 2002), while the low carbon contents were due to the relatively short time the iron was in contact with carbon during its extraction in the bloomery furnace (Blomgren and Tholander 1986). In addition, ancient irons always contain entrapped slag inclusions, of the order of few volume per cent, which is due to the method of iron extraction in the bloomery furnace and its subsequent processing. 
The aim of the present communication is to obtain insights on alloy design criteria for producing ductile phosphoric irons, based on microstructural characterization of archaeological Indian irons. The communication will critically address the important question of how the $\mathrm{P}$ segregation to the grain boundaries was avoided. The limitations of the present study should also be clearly understood. First, care must be exercised in the interpretation and extrapolation of data from archaeological to modern iron. Apart from the entrapped slag content, the distribution of $\mathrm{P}$ will be different in these irons. The macro-segregation of $\mathrm{P}$ in modern steels is quite different from the micro-segregation of $\mathrm{P}$ in archaeological irons. In modern steels, P occurs non-uniformly, especially in steels that have been cast. The last metal to freeze is rich in $\mathrm{P}$ and this local enrichment may remain in solid metal unless dispersed by a suitable heat treatment (for example, ingot soaking). This non-uniform $\mathrm{P}$ content will lead to degradation of mechanical properties, compared to a homogeneous steel. The phenomenon of homogenization of $\mathrm{P}$ content is well understood in the case of rephosphorized steels (for automotive applications) and therefore segregation of $\mathrm{P}$ is not anticipated to occur in modern phosphoric irons. The segregation of $\mathrm{P}$ observed in ancient irons, on the other hand, is microscopic in nature because the metal was never in the molten state during its extraction in the bloomery furnace, in which the iron ore was reduced in the solid state. The phosphorus micro-segregation in archaeological iron is a result of local dephosphorization processes in the presence of fayalitic slags (Kumar and Balasubramaniam 2002; Piccardo et al 2003) and high temperature metallurgical transformations (Stewart et al 2000). This will be addressed critically after understanding the mechanical behaviour of phosphoric irons.

\section{Mechanical behaviour}

Some results of tensile tests on iron-phosphorus and iron-carbon-phosphorus alloys are available (Stewart et al 2000). P increases the yield strength, ultimate tensile strength and hardness, but decreases both elongation and reduction in area at failure. Very high $\mathrm{P}$ contents promote brittle behaviour (Stewart et al 2000). Phosphorus causes solid solution strengthening, of the same order as interstitial carbon and nitrogen (Allen 1963). It also results in marked work hardening in iron when cold worked (Tylecote 1986).

Although $\mathrm{P}$ can promote cold short behaviour, it must be noted that phosphoric irons can be worked plastically at ambient temperatures provided it is not exposed to very low temperatures, high loading rates, does not possess specimen geometries which cause local stress concentration, and high carbon contents are avoided (Stewart et al 2000). In fact, the strain hardening exponent, which is a good measure of ductility of material under deformation processing operation (like, for example, wire drawing) of carbon-containing phosphoric irons (with $\mathrm{P}$ levels up to $0.12 \mathrm{wt} \%$ and carbon contents of $\sim 0.02$ wt.\%) (Hu 1976) are comparable to that of ferrous alloys (Zhang et al 1989; Mediratta et al 1990), while that of carbon-free phosphoric irons (with $\mathrm{P}$ levels up to 0.37 wt.\%) (Stewart et al 2000) are higher than that of ferrous alloys. The higher the strain hardening exponent, the ductility of the material is higher in deformation processing operations like wire drawing (Hu 1976; Dieter 1988). It is also important to consider the type of deformation processing operation while addressing the ductility of phosphoric irons, because of the stress-state created. For example, the limiting strain achievable in drawing is usually at least twice that in pure tension (Dieter 1988) and subsequently, this explains why phosphoric irons can be drawn with great ease (Goodway and Fisher 1988). It must also be noted that in drawing operation, the material is constrained by a die. It is realized that the different stress states that are generated during deformation processing produce and leave behind different patterns of residual strain, and this could also affect the mechanical properties. In fact, $\mathrm{P}$ at levels around $0.1 \mathrm{wt} \%$ is known to improve the strength and deep drawability of sheet steel used for automotive applications. Interestingly, the carbon contents are maintained at $<0.01 \mathrm{wt} \%$ to obtain high formability in this application (Hopkins and Tipler 1958; Suzuki et al 1985). Phosphoric irons can be easily hot forged (Percy 1864) and also cold worked under suitable conditions, like low strain rates and with geometries that avoid stress concentration (Stewart et al 2000). Stewart et al (2000) noticed that $\mathrm{Fe}-\mathrm{P}$ alloys could be easily hot forged at $900^{\circ} \mathrm{C}$ compared to $\mathrm{Fe}-\mathrm{C}$ alloys, which was explained partly to be due to stabilization of ferrite to high temperatures and the known fact that the hardness of ferrite drops rapidly below that of austenite at high temperatures (Gove and Charles 1974). Moreover, the pearlite transformation in $\mathrm{Fe}-\mathrm{C}$ alloys limited the temperature below which forging was feasible.

The most interesting fact about the effect of $\mathrm{P}$ on mechanical behaviour of modern iron is that the embrittling effect of $\mathrm{P}$ is reduced in the presence of small amounts of carbon (Allen 1963). For example, Suzuki et al (1985) found that the phosphoric irons with carbon concentrations about $0.01 \mathrm{wt} . \%$ displayed much more ductility than alloys with lower or higher carbon contents. Reducing the carbon content to $0.015 \%$ suppressed the onset of brittle failure in iron containing $0.15 \mathrm{wt} . \% \mathrm{P}$ (Josefsson 1954). As the carbon content is increased, the onset of brittle behaviour is associated with the precipitation of carbides which act as sites for fracture initiation (Josefsson 1954; Suzuki et al 1985). It is in this context that archaeological irons are interesting. Usually high $\mathrm{P}$ contents are found with low carbon contents in archaeo- 
logical irons and hence embrittlement was avoided. In fact, very little carbide can be observed in ancient phosphoric irons (Balasubramaniam 2002). As phosphoric irons were successfully used to manufacture tools in the past, it is conceivable that they possessed the required properties in order to be applied for this application by the ancient metallurgists. The distribution of slag inclusions in pre-industrial iron also determined the mechanical behaviour for $\mathrm{P}$ contents $<0.3 \mathrm{wt}$.\% (Gordon 1988).

There were several other applications where phosphoric irons were specifically utilized in ancient times. It was forged with iron of different compositions like in the case of steel cutting edge of knife joined to phosphoric iron for the knife back (Stewart et al 2000) and forging together of different iron compositions to produce pattern welded artefacts (Tylecote and Gilmour 1986; Piaskowski 1964). Phosphoric irons were sometimes avoided deliberately (Ehrenreich 1986), while at other times they were deliberately chosen, for example, in manufacture of harpsichord wire (Goodway and Fisher 1988).

\section{Microstructural investigations on ancient Indian irons}

It has been shown elsewhere that the ancient Indian iron smiths deliberately chose phosphoric irons when atmospheric corrosion resistance was desired (Balasubramaniam 2002). The beneficial effect of phosphorus in iron with respect to iron's superior atmospheric corrosion resistance has been well established, as revealed by the Delhi iron pillar (Balasubramaniam 2002). Therefore, the use of phosphoric irons in applications that require atmospheric corrosion resistance has been propounded (Balasubramaniam 2003). This idea is already being implemented in some grades of weathering steels (Misawa et al 1971). The beneficial effect of $\mathrm{P}$ on the corrosion resistance of iron could be one of the reasons why phosphoric irons are found well preserved in excavations, because they are presumably less susceptible to corrosion. In this regard, it is interesting to note the comment of Evans that the life period of archaeological irons fall on a distribution and the iron samples that are preserved are the ones in the tail end of this distribution (Wranglen 1970). As phosphorus is a common feature in all these irons, it therefore had an important role to play in their corrosion resistance.

The embrittling effect of $\mathrm{P}$ has lead people in the iron and steel making industry to eliminate as much $\mathrm{P}$ as possible from modern day steels. However, in the earlier section on the mechanical behaviour of phosphoric iron, it was seen that the ancient blacksmiths deliberately chose phosphoric irons for operations where ductility was required. In order to understand the possible method by which the ancient blacksmiths overcame the problem of embrittlement in phosphoric irons, a very careful study of the microstructures of several ancient Indian irons (dating from the 5th Century AD up to the 19th Century AD) was undertaken. The relevance of these microstructural observations in the microstructural design to produce ductile phosphoric iron will be highlighted below.

The specific example that shall be addressed is an iron clamp from the Gupta period temple at Deogarh. The Gupta temple at Deogarh has been conservatively dated to the 6th century AD (Vats 1952). The artistically meritorious stone sculptures from this temple have been critically acclaimed and well reported (Harle 1974). However, there is no mention of the large number of iron clamps that were used in holding together the stone blocks that formed the structure. The iron clamp utilized in the present investigation was obtained from the temple substructure. The clamp was found exposed to atmosphere when it was extracted for scientific studies. Samples for different investigations were sectioned from the iron clamp (figure 1). The microstructure of the iron clamp was obtained after sectioning the iron clamp. The composition of the sample, determined from a specimen cut from the clamp, was estimated by wet chemical analysis (using ICTP-AES) to be $0.30 \% \mathrm{P}, 0.21 \% \mathrm{Si}, 0.18 \% \mathrm{Al}$, $0.11 \% \mathrm{Ni}, 0.024 \% \mathrm{C}$ and $0.013 \% \mathrm{~S}$. The origin for $\mathrm{Ni}$ and $\mathrm{Al}$ in this ancient iron is not known. However, a careful analysis of local compositions in the microstructures using the compositional analysis unit in the SEM and EPMA (Piccardo et al 2003) did not reveal any other element apart from P. The Deogarh iron that was used for the analysis contained a high $\mathrm{P}$ content, and most importantly, a very low amount of carbon. Based on the survey of mechanical behaviour of $\mathrm{Fe}-\mathrm{P}$ and $\mathrm{Fe}-\mathrm{P}-\mathrm{C}$ alloys, it was anticipated that the deleterious effect of $\mathrm{P}$ would have been negated by the presence of a small amount of $\mathrm{C}$ in the Deogarh iron and therefore, this sample provided an excellent opportunity to understand microstructural design of ancient phosphoric irons.

In the un-etched condition, elongated slag inclusions were revealed (figure 2). They were distributed unevenly with no apparent regularity. In some regions, the volume fraction of the slag inclusions was higher than in other locations. This heterogeneous distribution of entrapped slag inclusions is a typical feature of ancient iron microstructures. Upon etching the polished surfaces with nital, microstructures typical of ancient Indian iron were revealed (Balasubramaniam 2002). The structure of the

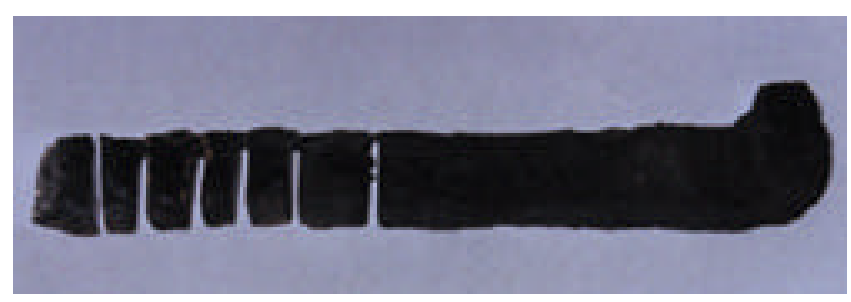

Figure 1. The iron clamp from the Gupta temple at Deogarh. 
wrought iron was essentially ferritic. This is understandable because of its low carbon content. The only other element identified by local compositional analysis in the SEM and EPMA in the iron matrix was phosphorus (Piccardo et al 2003). This was in conformity with the compositional analyses of several ancient Indian irons (Hadfield 1912; Neogi 1914). The phosphorus distribution in archaeological irons is non-uniform due to microsegregation that occurs during the extraction process (Vizcaino et al 1998a,b). Macrosegregation is not realized because the iron was never in the liquid state. Metallographic etching of ancient Indian phosphoric iron with nital reveals the so-called 'ghosting' effect, a wrinkled or watery appearance of the ferritic grains. An example of the same is shown in figure 3. The 'ghost' structure is due to high temperature metallurgical transformations and this has been discussed in detail elsewhere (Stewart et al 2000).

It has earlier been shown that the Oberhoffer etchant can be successfully employed to reveal $\mathrm{P}$ segregation in archaeological irons (Stewart et al 2000). The etch deposits $\mathrm{Cu}$ on regions low in $\mathrm{P}$ and therefore these regions appear dark in the optical microscope. Regions

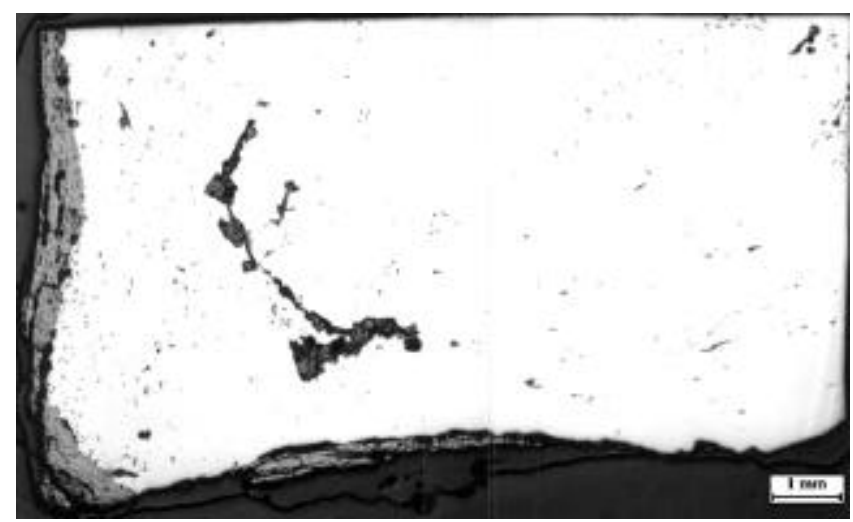

Figure 2. Microstructure in the unetched condition (Photograph courtesy: P Piccardo).

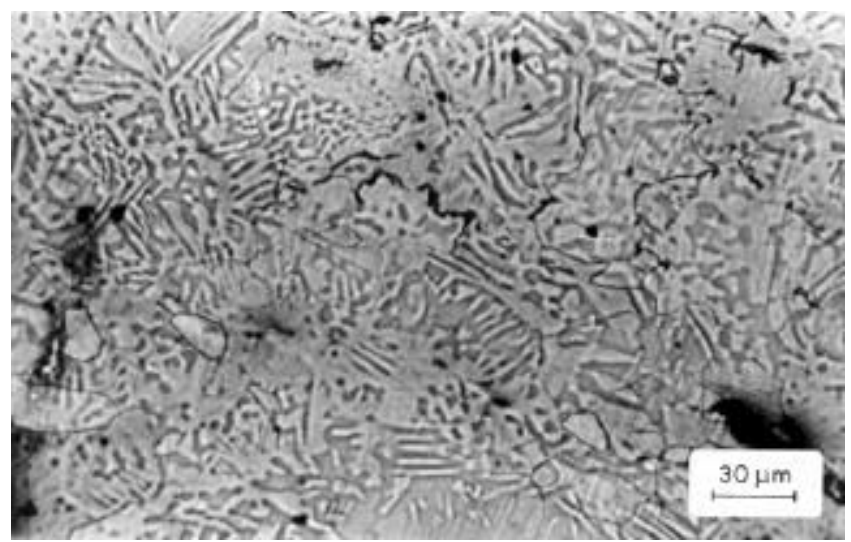

Figure 3. Microstructure of Dhar pillar iron after etching in nital. high in $\mathrm{P}$ appear bright because of lower $\mathrm{Cu}$ deposition. The Oberhoffer etchant was used to understand micro segregation of $\mathrm{P}$ in the Deogarh iron. The microstructure revealed areas that were depleted in $\mathrm{P}$ near the slag inclusions (figure $4 \mathrm{a}$ ). The variation in $\mathrm{P}$ concentration was observed by the different grades of gray colouration, with the regions low in $\mathrm{P}$ appearing more grayish than regions high in $\mathrm{P}$, which appeared light coloured (figure $4 \mathrm{~b}$ ). The regions adjoining the entrapped slag inclusions were generally devoid of $\mathrm{P}$, due to dephosphorization by the slag. This is also a typical characteristic of ancient Indian iron (Dillman and Balasubramaniam 2001). This was also confirmed by profiling the $\mathrm{P}$ concentration as a function of distance from the slag-metal interface in the EPMA. The regions immediately surrounding the inclusion were depleted of $\mathrm{P}$, thereby confirming the Oberhoffer etchant results. The $\mathrm{P}$ content in the matrix was not strictly uniform, although it was relatively on the higher side. The $\mathrm{P}$ content of the iron determined by wet chemical analysis was in accordance with the $\mathrm{P}$ concentration in the matrix
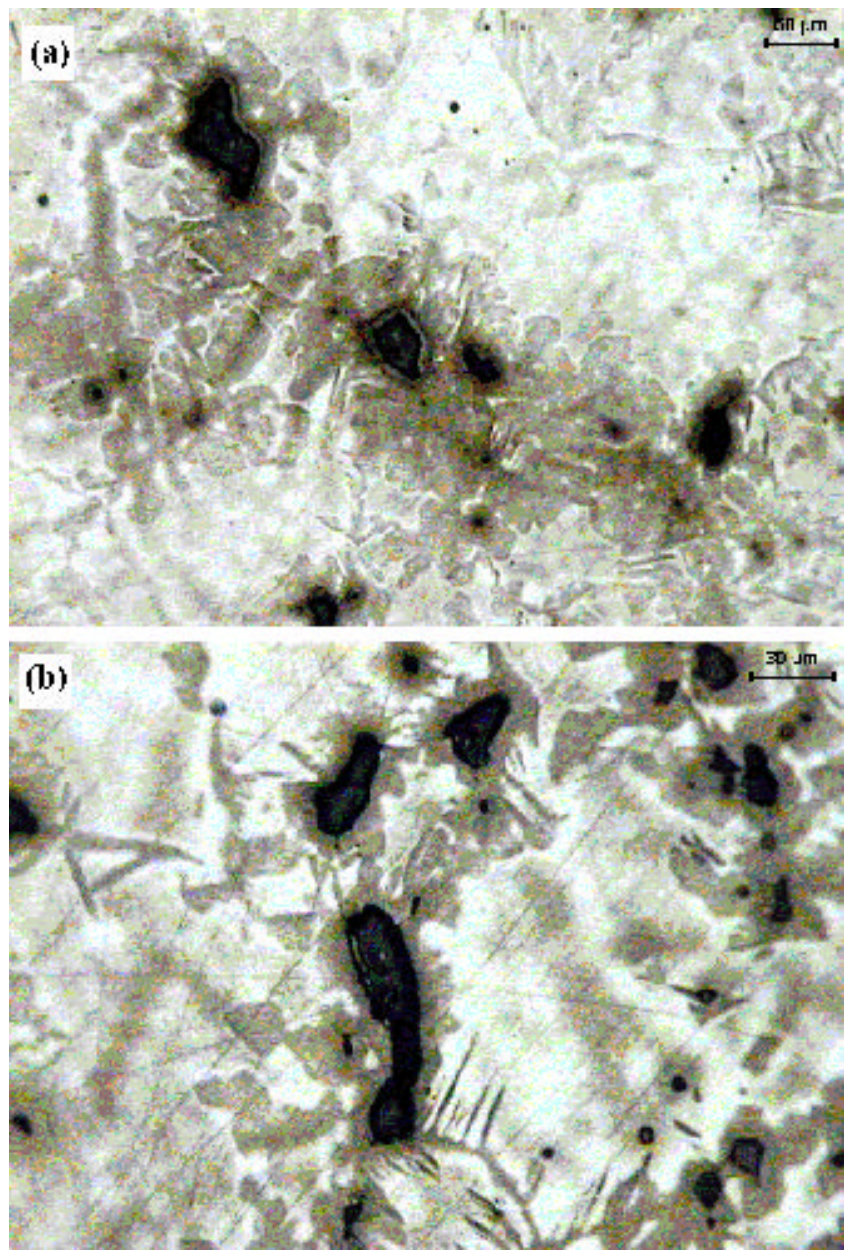

Figure 4. Optical microstructure of the iron after etching in Oberhoffer etchant. The $\mathrm{P}$ depleted regions appear dark in the microstructure. Notice $\mathrm{P}$ depletion next to the entrapped slag inclusions (Photographs courtesy: P Dillmann). 
determined by the EPMA. Another interesting feature observed after etching with Oberhoffer etchant was that the grain boundaries were depleted of $\mathrm{P}$, as revealed by the darker hue at these locations (see figure $4 \mathrm{~b}$ ). The allotriomorphic and Widmanstatten 'ghost' structures of the prior austenite phase along the grain boundary regions (figure 4b) after etching in Oberhoffer etchant have been addressed in detail elsewhere (Stewart et al 2000; Piccardo et al 2003). A suitable soaking treatment of the phosphoric iron in the two phase gamma + alpha region of the Fe-P phase diagram (figure 5) will lead to precipitation of gamma phase along the alpha phase grain boundaries. As the gamma phase (austenite) possesses a lower $\mathrm{P}$ solubility, the segregation of $\mathrm{P}$ to the grain boundary regions can be avoided. On later cooling down the sample to room temperatures at an appropriate cooling rate, all the allotriomorphic and Widmanstatten austenite along the grain boundaries will transform by massive transformation to ferrite. However, the differences in phosphorus composition between the grain boundary and interior grains will remain even after the grain boundary austenite has transformed to ferrite, if appropriate cooling rates are selected after the high temperature anneal. It is this difference in $\mathrm{P}$ composition that results in 'ghost' structures on etching with Oberhoffer or nital etchants. Therefore, the first important idea to avoid $\mathrm{P}$ segregation along the grain boundaries is to create the right soaking conditions (for example, before the bar mill rolling operation) in order to precipitate austenite allotriomorphs along ferrite grain boundaries.

The low magnification study in the optical microscope clearly revealed that $\mathrm{P}$ was depleted near the grain boundaries, the location where it causes the maximum problem. When the Deogarh iron microstructure was viewed in the scanning electron microscope (SEM), the grain boundaries were revealed only in some areas. However, the slag inclusions were very well delineated in the SEM. At several locations in the material, the grain boundaries were difficult to distinguish after the nital etch, especially in the regions where the microstructure was highly deformed. This was also in tune with modern studies on phosphoric iron (Stewart et al 2000) where it was reported that it was difficult to etch the grain boundaries in $\mathrm{Fe}-\mathrm{P}$ alloys from near the necked region of
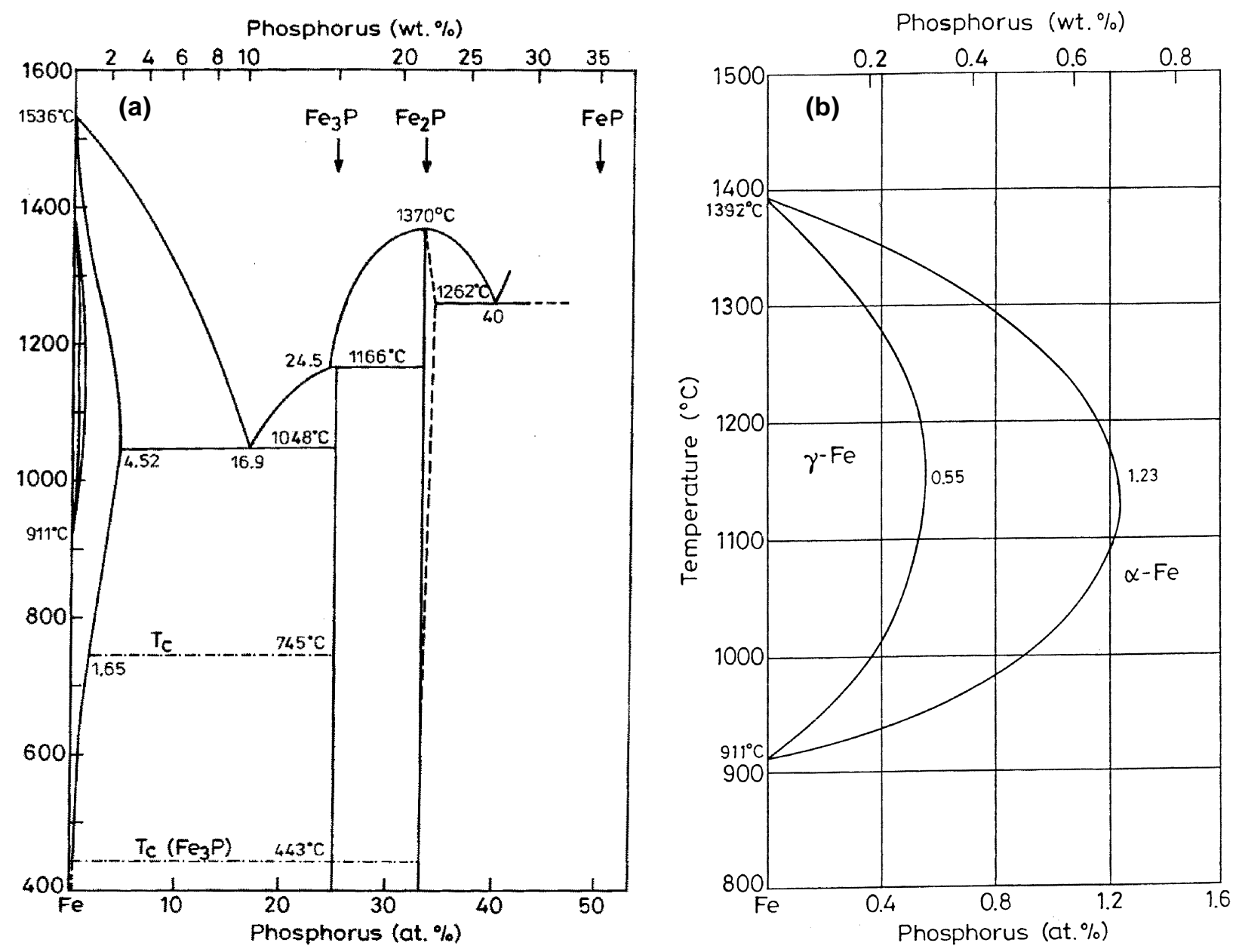

Figure 5. (a) Fe-P binary phase diagram, and (b) high temperature gamma loop region of the Fe-P phase diagram (Kubaschewski 1982). 
tensile test samples because of the high degree of deformation in this region. Of course, the biggest advantage of using the SEM is that local compositions of the entrapped slag inclusions could be determined by EDS or WDS. However, SEM observations could not shed insights on the role of $\mathrm{P}$ in the matrix and the grain boundaries. It is for this reason that the sample was viewed at much higher resolution in the transmission electron microscope (TEM). The TEM observations reported in this communication are the first for archaeological Indian iron. Further, alloy design criteria to produce ductile phosphoric irons would be addressed based on the TEM observations.

Thin slices were cut out from the clamp using a slow speed diamond saw. The slices were mechanically thinned to a thickness of around $100 \mu \mathrm{m}$, and $3 \mathrm{~mm}$ diameter discs were punched out from the thinned slices. The final polishing was performed in a twin jet electrolytic polishing unit utilizing a perchloric acid + glacial acetic acid (ratio $1: 9$ by volume) mixture $\left(5-10^{\circ} \mathrm{C}\right)$ at $30 \mathrm{~V}$ and $0 \cdot 5 \mathrm{~A} \cdot \mathrm{cm}^{-2}$. TEM observations were made on a JEOL 2000FX microscope operating at $160 \mathrm{kV}$.

The general observation in the TEM was that the microstructures were heterogeneous, thereby confirming that the heterogeneity of the sample was maintained even up to the fine scale. Additionally, several different kinds of second phase particles were observed at high magnifications. Interestingly, the size of the second phase particles varied between nanometer and micrometer scales. A typical TEM microstructure of Deogarh iron, from a region close to a slag-rich area, is shown in figure 6 . The grain boundary characteristics and the grain boundary phase varied depending upon their origin and surroundings. A medium sized slag particle has been marked $\mathrm{S}$ in the micrograph of figure 6 . The slag-smeared grain boundary in this region (marked GB) can be observed.

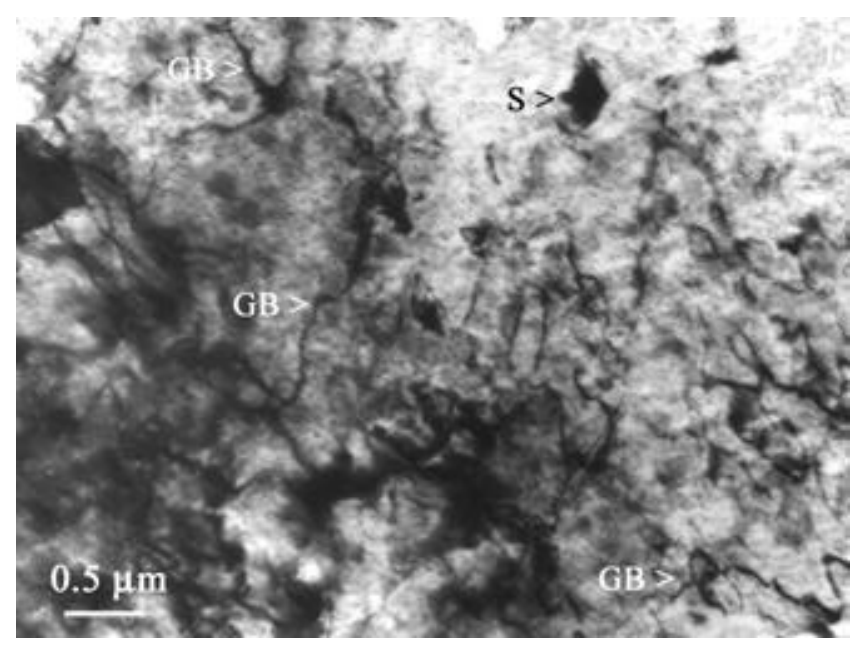

Figure 6. Transmission electron micrograph of a region close to a slag particle. A slag particle is marked $\mathrm{S}$ and the slag smeared grain boundary in this region (marked GB) is readily evident.
This must have presumably occurred during the extraction process when the liquid/mushy state slag could have spread along the grain boundaries. The irregular shape taken by the grain boundaries and also the slag phase (dark contrast phase) is well illustrated in figure 7 and few such boundaries are marked GB (indicated by arrow). Therefore, the second important idea for alloy design to produce ductile phosphoric iron (by not allowing $\mathrm{P}$ to segregate to the grain boundaries) is to locate some other phase/element at the grain boundaries such that $\mathrm{P}$ is not allowed to segregate there. In this regard, the presence of the smeared layer of slag phase along the grain boundaries in ancient irons avoids $\mathrm{P}$ segregation to these interfaces. In case of modern phosphoric iron, this must be achieved by other means, for example, by precipitation of carbide or segregation of carbon to the grain boundary regions. In this context, even at very low concentrations of $0.02 \%, \mathrm{C}$ can segregate to the boundaries as a very thin layer. This could prevent phosphide phase formation along the boundaries. When carbon is present in the grain boundaries either in the form of free carbon or in the form of carbides, it prevents $\mathrm{P}$ from segregating to these locations. This should be relatively easy to achieve and control because it is well known that carbon will segregate to regions that are poor in $\mathrm{P}$ and vice versa (Bramley et al 1935). This is based on the fact that $\mathrm{C}$ is an interstitial solute whereas $\mathrm{P}$ is a substitutional solute. As the strain fields set-up by these solutes are different and opposite, strain energy considerations will not permit $\mathrm{C}$ and $\mathrm{P}$ to be located at the same region. Of course, the precipitation of a high amount of carbide in phosphoric iron has been determined to be deleterious to the ductility based on studies on modern iron (Stewart et al 2000), and therefore, this implies that $\mathrm{C}$ content must be kept low and carefully controlled.

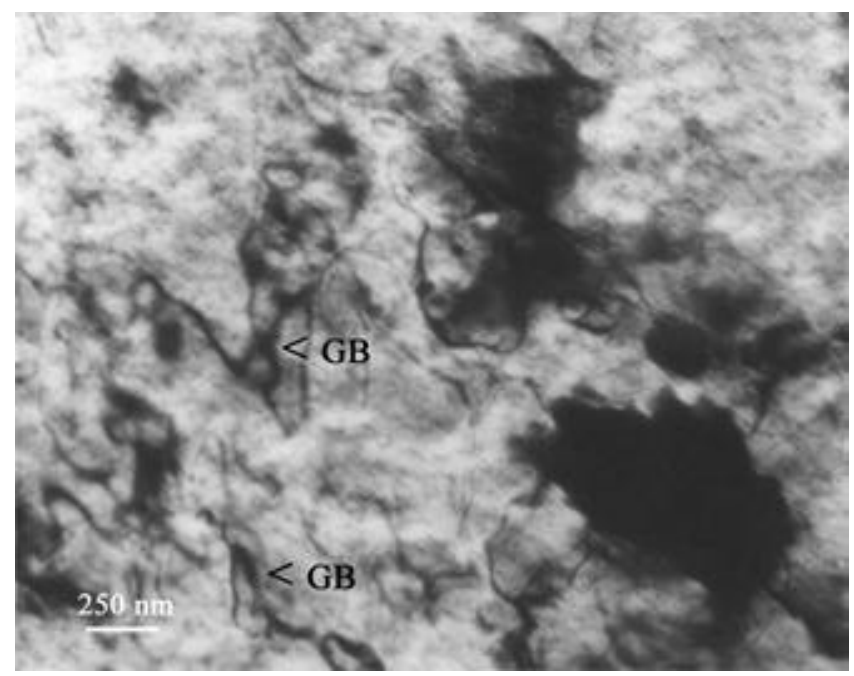

Figure 7. Electron micrograph illustrating the irregular shape slag phase (dark contrast phase) smeared grain boundaries. A few such boundaries are marked GB and indicated by arrows. 
Another important feature observed in the Deogarh iron was the presence of fine scale precipitates throughout the matrix. The micrograph shown in figure 8 clearly delineates these very fine precipitates throughout the ferrite grain. The precipitates were $<20 \mathrm{~nm}$ in size and were rather uniformly distributed in regions where they were found (figure 8). For the $\mathrm{P}$ contents encountered in archaeological irons, the $\mathrm{Fe}-\mathrm{P}$ phase diagram (figure 5) predicts precipitation of phosphide phase, $\mathrm{Fe}_{3} \mathrm{P}$. It can be concluded from the $\mathrm{Fe}-\mathrm{P}$ phase diagram that $\mathrm{P}$ in solid solution in ferrite, after extraction and processing, precipitates as $\mathrm{Fe}_{3} \mathrm{P}$ during cooling to room temperature. There could have been further growth during room temperature aging

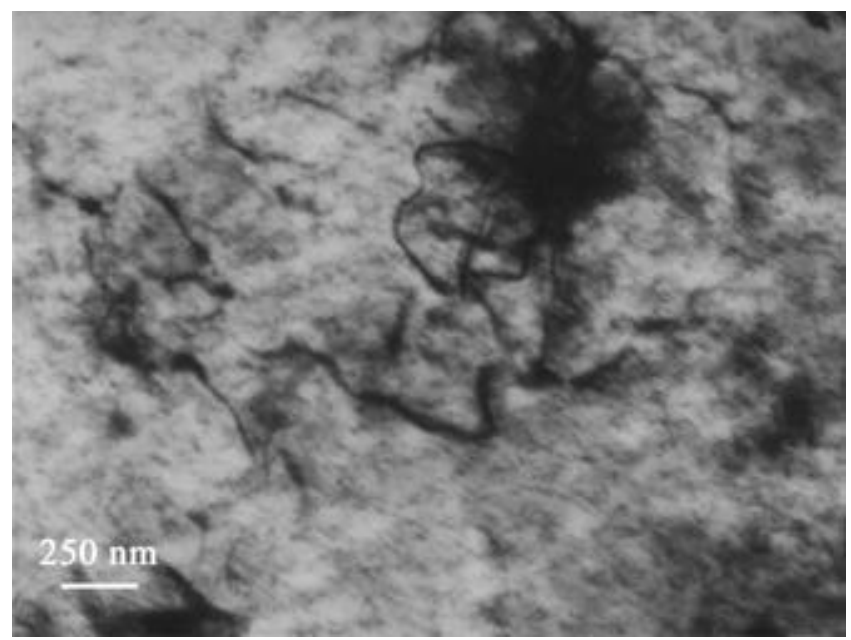

Figure 8. Micrograph clearly delineating very fine precipitates of size $<20 \mathrm{~nm}$ uniformly distributed throughout the ferrite grain.

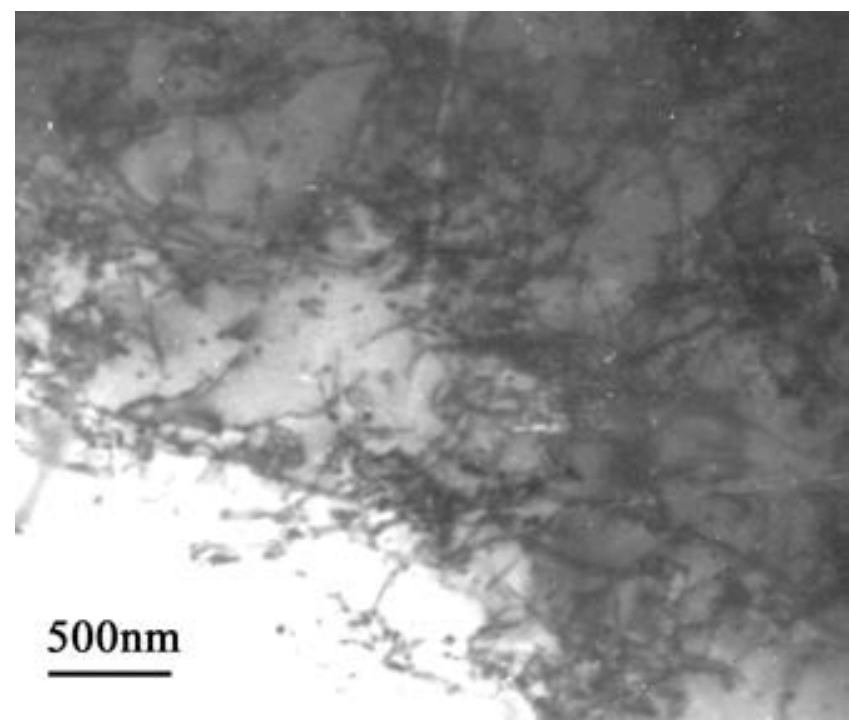

Figure 9. TEM picture depicting the microstructural details in the ferrite grain interior. The high density of dislocation, both as individual dislocations and in those forming a cell structure can be seen. for hundreds of years, but its extent must be very minimal because of kinetic barriers to growth at ambient temperatures. This is probably the reason for the phosphide precipitates appearing very fine. As the phosphide phase was not detected near the grain boundaries, it is therefore obvious that there was not enough $\mathrm{P}$ at these locations to precipitate this phase. In view of the above observation, the third important criterion, for producing ductile phosphoric iron, is that the $\mathrm{P}$ in solid solution in the ferrite matrix could be precipitated as very fine coherent $\mathrm{P}$ rich

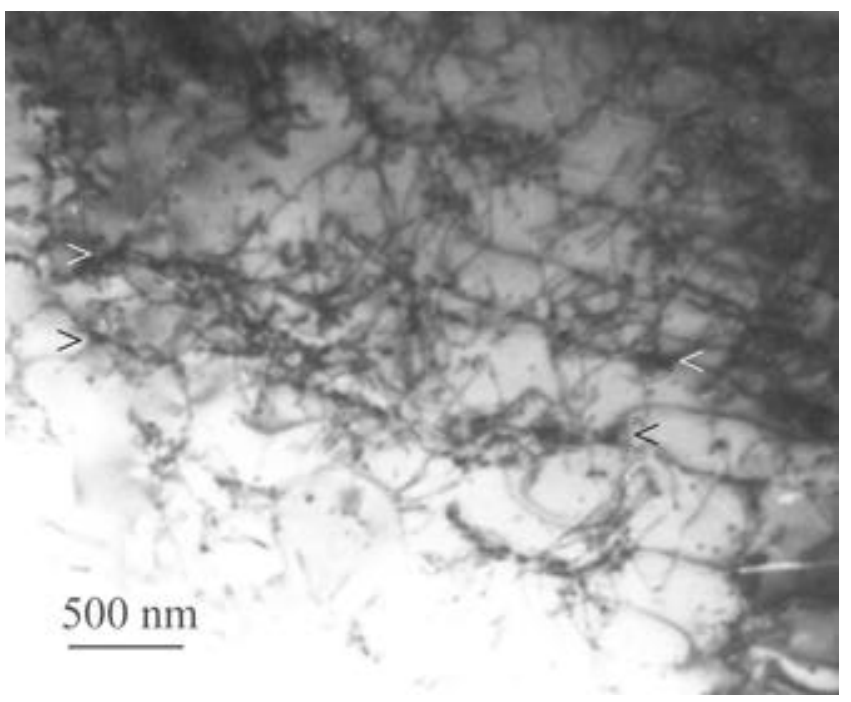

Figure 10. Micrograph illustrating the sub-grain formation and its microstructural details. The arrows indicate the second phase particles at the sub-grain boundaries. The second phase particles being preferentially present along the deformation bonds/sub-grain boundaries extending from left to right in the middle of the micrograph can be easily visualized.

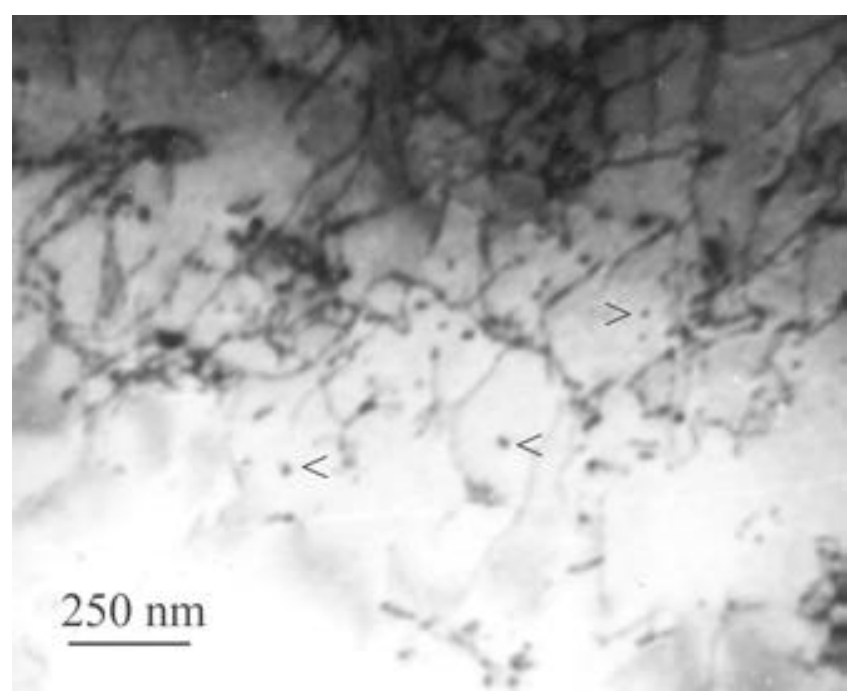

Figure 11. Micrograph illustrating the fine particles (indicated by arrows) within the ferrite grain/sub-grains interior of size $20 \mathrm{~nm}$ or less. 
precipitates in the ferrite grain interior, thereby avoiding $\mathrm{P}$ segregation to the boundaries as well as achieving higher strengths.

The microstructural details in the ferrite grain interior are illustrated in the TEM micrograph of figure 9. Cell formation was clearly observed. At several locations, sub-grain formation was demonstrated, as seen in the example in figure 10. The fine nature of the sub-grains must be related to the presence of phosphorus because it is known that $\mathrm{P}$ in iron reduces the grain size. The arrows
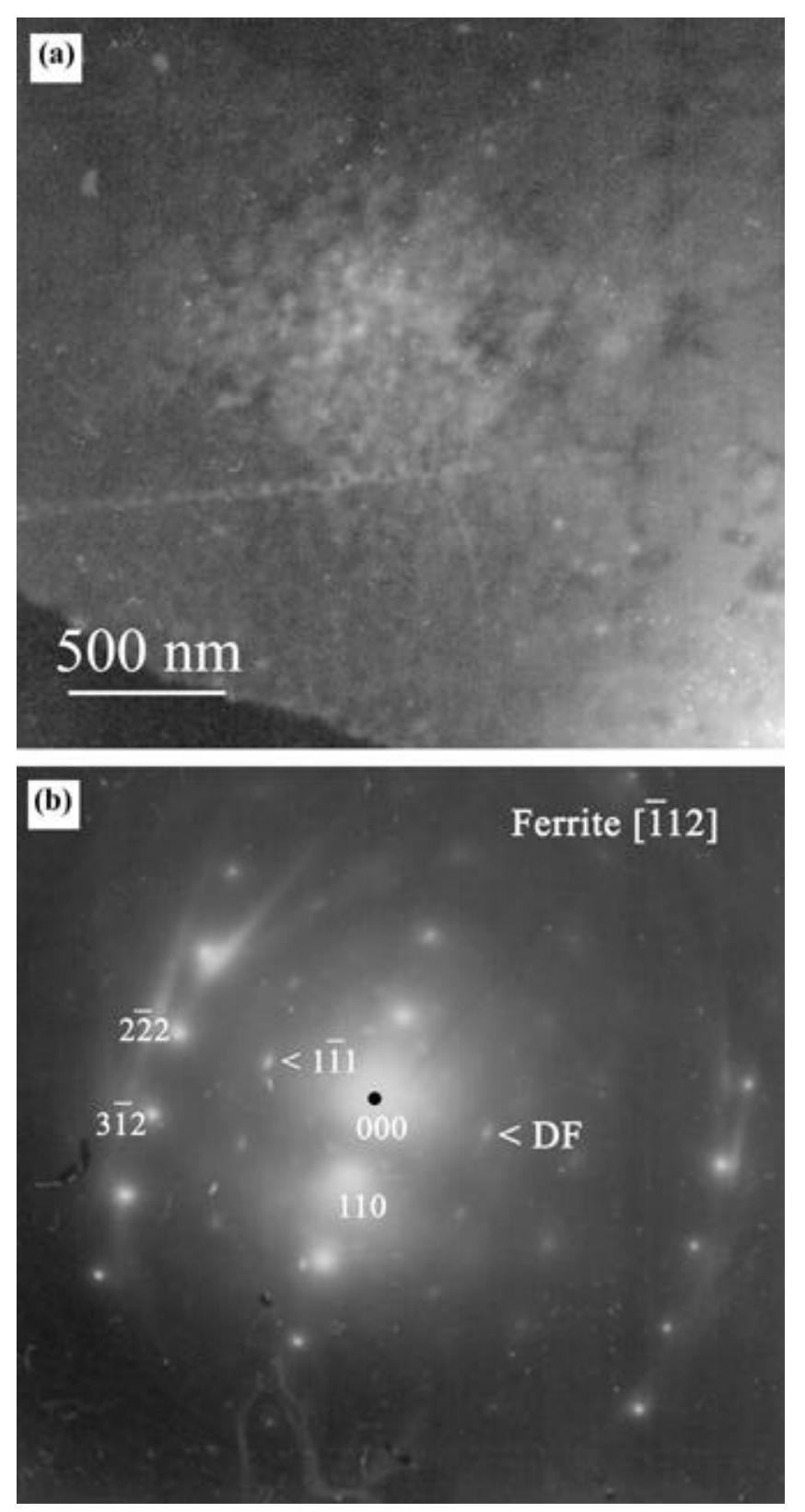

Figure 12. Electron micrograph showing ordered domain like features in localized regions: (a) dark field image; and (b) selected area diffraction pattern from the corresponding area, and the extra spot due to ordering used for dark field is marked DF. in figure 10 indicate the second phase particles at the subgrain boundaries. The second phase particles being preferentially present along the deformation bands/sub-grain boundaries extending from left-top to right-bottom can be easily visualized from this TEM micrograph. Figure 11 illustrates certain fine particles (indicated by arrows) within the ferrite grain/sub-grains in the size range of $20 \mathrm{~nm}$ or less.

In several locations, ordered domain-like features have been identified. The selected area diffraction pattern from the corresponding areas exhibited extra reflections. Figure 12a shows one such domain in a dark field image using the extra spot indicated in the selected area diffraction pattern (SADP) shown in figure 12b. The SADP is found to be from $\langle 112\rangle$ zone and the $\{111\}$ reflection is due to ordered $b c c$ structure. Figure 13 shows the domain structure in bright field image from another region of the sample at relatively higher magnification. These ordered domains are larger in size compared to those shown in figure 12a. As the local compositions were rich in $\mathrm{P}$, the domains should presumably result due to $\mathrm{Fe}-\mathrm{P}$ ordering. These aspects are being further investigated.

\section{Conclusions}

Alloy design criteria for producing ductile phosphoric irons have been proposed based on microstructural studies in ancient Indian irons. The alloy design calls for avoiding $\mathrm{P}$ segregation to the grain boundaries by precipitating austenite allotriomorphs, by utilizing a critical amount of carbon to segregate carbon/precipitate carbide at grain boundaries and by precipitating some of the $\mathrm{P}$ in solid solution in the form of fine coherent phosphide precipitates in the matrix.

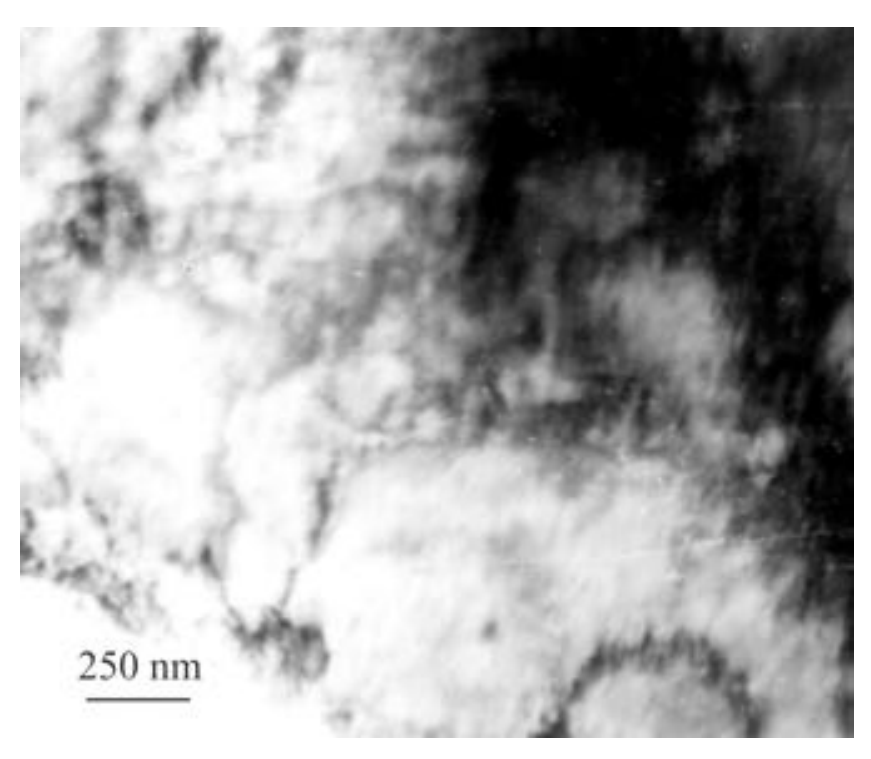

Figure 13. Bright field image of the domain structure at higher magnification. 


\section{Acknowledgement}

The authors acknowledge the useful discussions on phosphorus in steels with Prof. L K Singhal, Materials and Metallurgical Engineering Department, IIT Kanpur.

\section{References}

Allen N P 1963 in Iron and its dilute solid solutions (eds) C W Spencer and F E Werner (New York: Wiley Interscience) pp 271-308

Balasubramaniam R 2000 Corros. Sci. 422103

Balasubramaniam R 2002 Delhi iron pillar-New insights (Shimla: Indian Institute of Advanced Study)

Balasubramaniam R 2003 Curr. Sci. 84126

Blomgren S and Tholander E 1986 Scand. J. Metall. 15151

Boyer H E and Gall T L 1990 Metals handbook (Metals Park, USA: ASM International) 10 ed., Vol. 1, p. 144

Bramley A, Haywood F W, Coopers A T and Watts J T 1935 Trans. Faraday Soc. 31707

Dieter G E 1988 Mechanical metallurgy (London: McGrawHill) 3rd ed.

Dillmann P and Balasubramaniam R 2001 Bull. Mater. Sci. 24 317

Ehrenreich R M 1986 Oxford J. Archaeol. 5165

Goodway M and Fisher R M 1988 Hist. Metall. 2221

Gordon R G 1988 Archaeomaterials 2109

Gove K B and Charles J A 1974 Met. Technol. 1279

Hadfield R 1912 J. Iron and Steel Inst. 85134

Haensel H and Grabke H J 1986 Scr. Metall. 201641

Harle J C 1974 Gupta sculpture: Indian sculpture of the fourth to the sixth centuries $A D$ (Oxford: Clarendon Press)

Honeycombe R W K and Bhadeshia H K D 1995 Steels-Microstructure and properties (London: Edward Arnold) 2nd ed.

Hopkins B E and Tipler H R 1958 J. Iron Steel Inst. 188218

Hu H 1976 Texture Cryst. Solids 2113
Inman M C and Tipler H R 1958 Acta Metall. 673

Josefsson A 1954 J. Iron Steel Inst. 117118

Kubaschewski O 1982 Iron-Binary phase diagrams (Berlin: Springer Verlag) pp 84-86

Kumar V and Balasubramaniam R 2002 Metals, Mater. and Process. 141

Mcdonnel G 1989 World Archaeol. 20373

Mediratta S R, Ramaswamy V, Singh V and Rama Rao P 1990 J. Mater. Sci. Lett. 9205

Menyhard M 1992 Scr. Metall. 261695

Misawa T, Kyuno T, Suetaka W and Shimodaira S 1971 Corros. Sci. 1135

Neogi P 1914 Iron in ancient India (Calcutta: Indian Association for the Cultivation of Science)

Percy J 1864 Metallurgy —Iron and steel (London: John Murray)

Piaskowski J 1964 J. Iron Steel Inst. 202561

Piccardo P, Ienco M G, Balasubramaniam R and Dillmann P 2003 Curr. Sci. (communicated)

Sakurai T, Kuk Y, Birchenall A K, Pickering H W and Grabke H J 1981 Scr. Metall. 15535

Stead J E 1918 J. Iron Steel. Inst. 97389

Stewart J W, Charles J A and Wallach E R 2000 Mater. Sci. Technol. 16 275, 283, 291

Suzuki S, Obata M, Abiko K and Kumura H 1985 Trans. ISIJ 2562

Tylecote R E 1986 The prehistory of metallurgy in the British isles (London: The Institute of Metals)

Tylecote R F and Gilmour B 1986 The metallography of early ferrous edge tools and edged weapons (Oxford: BAR) p. 155

Vats M S 1952 The Gupta temple at Deogarh, Memoirs of the Archaeological Survey of India

Vizcaino A, Budd P and McDonnel J G 1988a Bull. Mater. Mus. 2913

Vizcaino A, McColm I J and McDonnel J G 1988b Bull. Mater. Mus. 3038

Wranglen G 1970 Corros. Sci. 10761

Zhang E, Huang M and Shi D 1989 Mater. Sci. Engg. A122 211 